\title{
SURGICAL TREATMENT OF ACQUIRED TRICUSPID STENOSIS
}

\author{
BY \\ JUDSON T. CHESTERMAN AND WILLIAM WHITAKER \\ From the Department of Thoracic Surgery and the Regional Cardiovascular Centre, the City General \\ Hospital, Sheffield, and the University Department of Medicine, the Royal Hospital, Sheffield
}

(RECEIVED FOR PUBLICATION AUGUST 29, 1955)

Tricuspid stenosis has now come within the ambit of surgery, and, as always, the possibility of surgical intervention demands an accuracy of diagnosis which was previously unnecessary and usually unattained.

Acquired tricuspid stenosis was known to Morgagni in 1761 , and, in spite of its rarity when compared with mitral and aortic disease, Rolleston (1941) reported that Leudet was able to collect 114 cases in 1888 . The incidence of the involvement of the individual valves in chronic rheumatic carditis is given by Wood (1954) as mitral $80 \%$, aortic $48 \%$, tricuspid $12 \%$, and pulmonary $5 \%$. Wood (1954) further states that at a " conservative estimate" 3,000 mitral valvotomies should be carried out annually in Great Britain, and it therefore seems probable that about 50 tricuspid valvotomies a year is an appropriate figure on the basis that about $15 \%$ of cases of tricuspid disease have predominantly stenotic lesions.

\section{Diagnosis}

There are certain features in the history of a patient who is suffering from a chronic cardiac lesion which suggest the possibility of tricuspid disease. First, Thompson and Levine (1937) point out that any adult patient who has repeated attacks of oedema and ascites, and yet is able to lead a sedentary life with the aid of diuretics and carry on with symptoms that ordinarily would cause his early demise, probably has tricuspid stenosis. Second, Cooke and White (1941) stress that a patient with rheumatic carditis and ascites who is able to sleep without extra pillows probably has tricuspid stenosis, which accounts for the absence of pulmonary congestion. Finally orthopnoea, usually a terminal symptom, may, according to Altschule and Blumgart (1937), be early and incapacitating if the systemic venous congestion is so marked that it rises to a level corresponding approximately to that of the respiratory centres in the brain. In less marked cases com- plaint may be made of fullness and congestion of the face and head.

The first glance at the patient is often suggestive of tricuspid disease on account of the bronze coloration of the face, which is best seen on the temporal region of the forehead and by the sides of the nose. This coloration, known as Shattuck's sign, has been attributed by Altschule and Blumgart (1937) and Altschule and Budnitz (1940) to a combination of cyanosis and jaundice, the former occurring in dilated cutaneous veins and venules and the latter being due to liver insufficiency. However, the pigmentation may be present in patients without elevation of the serum bilirubin level, suggesting that jaundice is not an important factor in its production. Skin biopsies from pigmented areas of the forehead show no abnormal pigment such as haemosiderin, and the coloration is probably due to an increased melanin content although such an increase cannot be detected by ordinary histological examination. It has been observed to disappear some months after a successful tricuspid valvotomy (Case 2).

Closer observation shows abnormal distension and pulsation of the veins of the neck. In patients with sinus rhythm giant "a" waves, with their characteristic sudden rise in presystole and rapid fall, are visible in the jugular venous pulse when there is tricuspid stenosis. These giant "a " waves are associated with increased right atrial pulse pressure. In chronic rheumatic heart disease they are usually related to pulmonary hypertension or tricuspid sienosis, and the latter is recognized as the probable cause by the exclusion of the former. Whitaker (1954) has pointed out that the clinical recognition of pulmonary hypertension in patients with mitral stenosis is made by noting a systolic lift over the right ventricular outflow tract, a palpable second heart sound, auscultating a split second heart sound with a loud second component, combined with radiological evidence of prominent pulmonary arteries and electrocardiographic signs of right ventricular hypertrophy. 


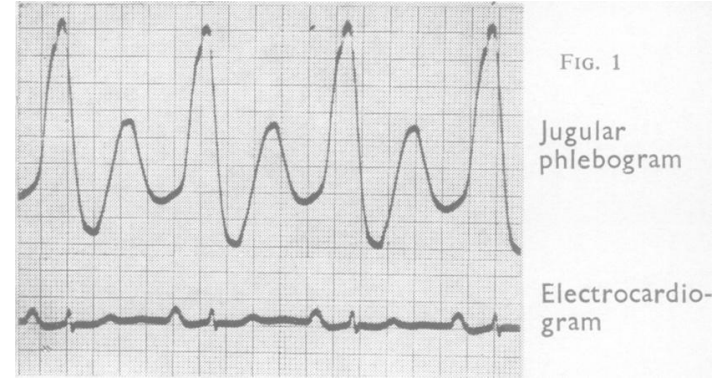

FIG. 1.-Synchronous records of the electrocardiogram and the jugular phlebogram showing giant "a" waves in a patient with tricuspid stenosis (Case 2).

Fig. 2.-Postero-anterior teleradiographs showing right atrial enlargement, all cases; normal pulmonary arteries, Cases 2 (tricuspid stenosis) and 1 (tricuspid and mitral stenosis); enlarged pulmonary arteries, Case 4 (advanced tricuspid and mitral stenosis with mean pulmonary arterial blood pressure of $55 \mathrm{~mm} . \mathrm{Hg})$; and pericardial effusion and pericardial adhesions Case 3 (advanced tricuspid and mitral stenosis).

FIG. 2
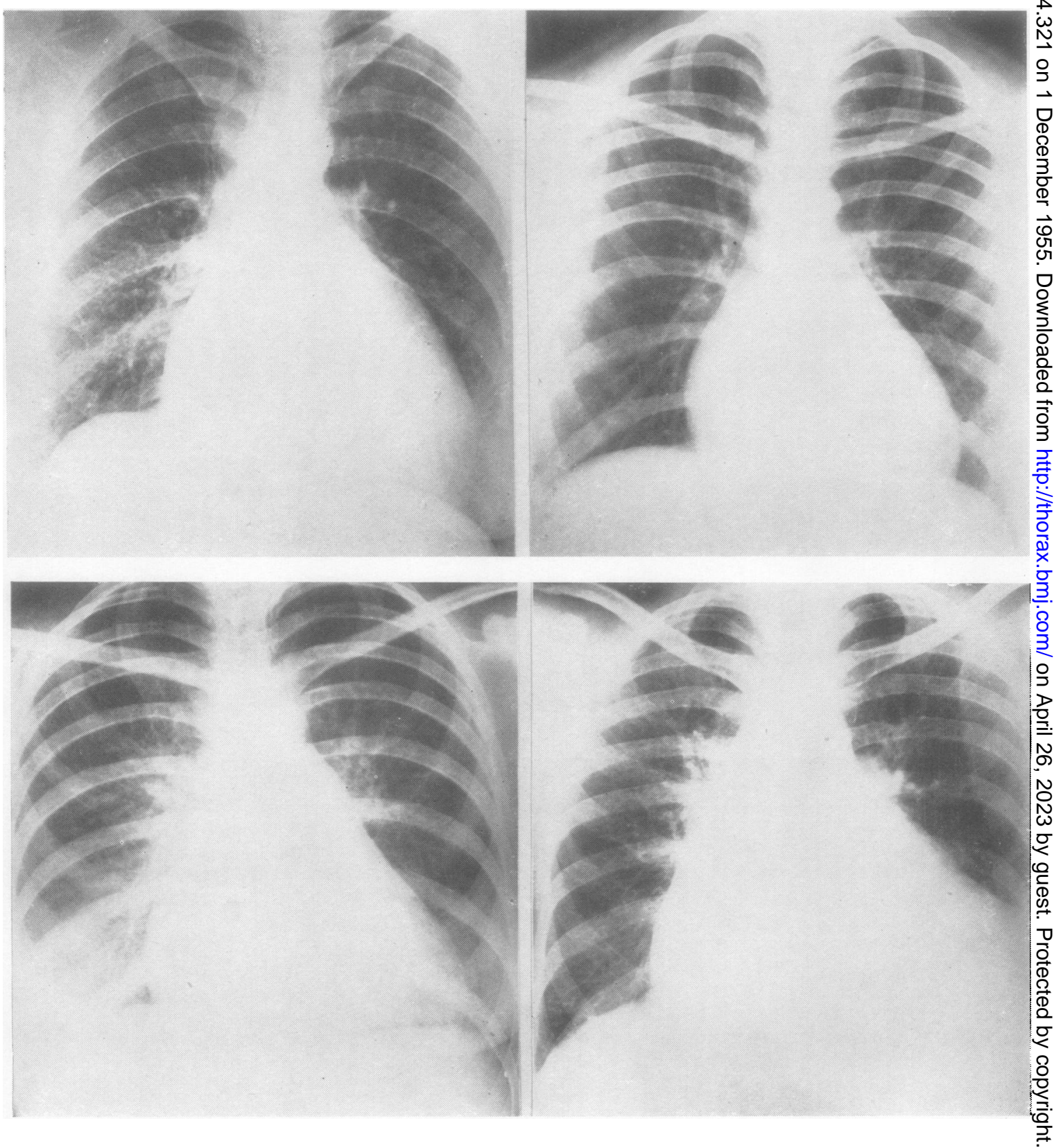
The phlebogram in tricuspid stenosis when auricular fibrillation is present is of doubtful significance.

The increased right atrial pulse pressure produces not only giant " $a$ " waves in the venous pulse, but is also transmitted to the liver to give a presystolic pulsation of the liver which must be differentiated from the systolic pulsation characteristically associated with tricuspid incompetence.

Auscultation may show a diastolic murmur localized to the lower left border of the sternum, but sometimes it may be either central in position or - even to the right of the midline in the region of the fourth and fifth costal cartilages. Difficulty is experienced owing to the trivalvular nature of many of these cases and by the all but invariable involvement of the mitral valve.

Careful auscultation may suggest tricuspid stenosis by the localization of the murmurs and their lessening intensity in passing between their maximum sites at the lower end of the sternum and the mitral area. The tricuspid diastolic murmur may be further accentuated by listening during

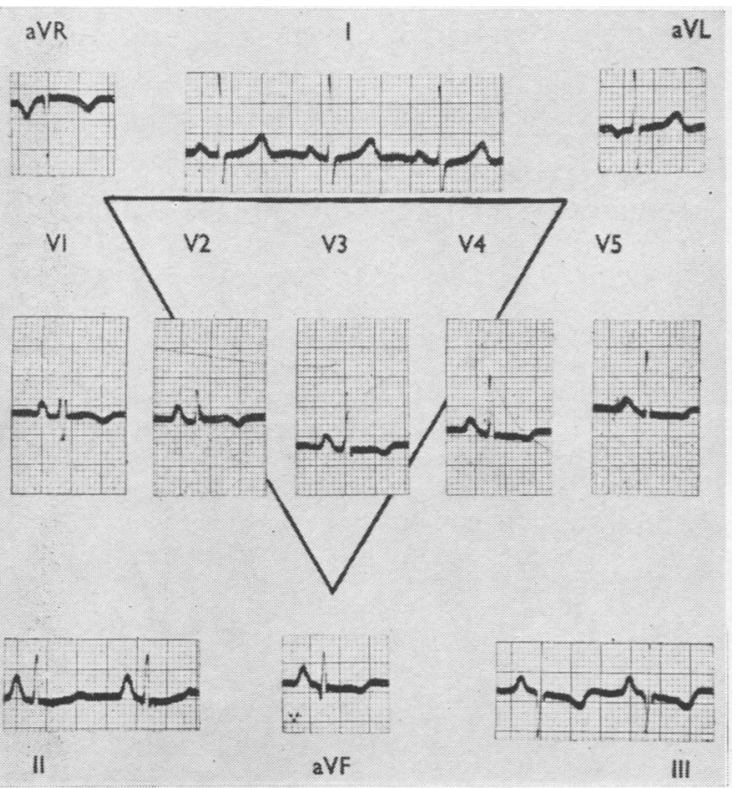

Fig. 3.-Electrocardiograms recorded before operation. The tall pointed $P$ waves in lead II are evidence of tricuspid stenosis in Case 2, tricuspid stenosis in Case 1, tricuspid and mitral stenosis without pulmonary arterial hypertension in Case 4, tricuspid and mitral stenosis with mean pulmonary arterial hypertension of $55 \mathrm{~mm}$. $\mathrm{Hg}$. 
inspiration and with the patient lying on the right side, in contradistinction to the mitral diastolic murmur, which is best heard with the patient lying on the left side and in expiration. In some cases the tricuspid murmurs are of a higher frequency and resemble the cry of a seagull. This " sea-gull " murmur may be diastolic or systolic, presumably depending on the main lesion in the valve.

The tricuspid diastolic murmur is of significance when present, but its absence does not exclude tricuspid stenosis, as murmurs originating from mitral valvular disease may render inaudible any sounds produced at the tricuspid valve. Kossmann (1955) has recorded an "opening snap" in tricuspid stenosis, and Wood (1950) states that there may be a localized thrill at the lower end of the sternum. Phonocardiography has not proved a diagnostic aid in our experience.

Radiological examination shows definite right atrial enlargement. Normal pulmonary arteries are seen except in the more uncommon case when pulmonary hypertension due to mitral stenosis is present. The oesophagus is displaced posteriorly. Grossly increased pericardial fluid may be found in advanced cases and is attributed by Altschule and Budnitz (1940) to the high venous pressure in the coronary sinus.

Electrocardiography may be suggestive if showing in lead II the increased and pointed $P$ wave of right atrial hypertrophy rather than the flatter or even bifid $\mathbf{P}$ wave of left atrial hypertrophy together with the absence of ventricular hypertrophy. However, as Smith and Levine (1942) found auricular fibrillation in $55 \%$ of their cases of tricuspid stenosis and as other valvular lesions are almost invariably present, the electrocardiogram may not be of much diagnostic value.

The clinical diagnosis of tricuspid stenosis may be made by noting the giant " $a$ " waves, the absence of pulmonary hypertension, the presence of the typical tricuspid diastolic murmurs, and the electrocardiographic evidence of an increased and pointed $P$ wave in lead II. However, some of these diagnostic points may be absent or equivocal in patients with tricuspid stenosis. In that case the pathognomonic sign is the altered pressure gradient found on cardiac catheterization of the right side of the heart. Normally the diastolic blood pressures in the right atrium and the right ventricle are equal. When tricuspid stenosis is present the atrial diastolic blood pressure is raised above that of the ventricle, and in patients with sinus rhythm the atrial pulse pressure is abnormally high and the pulse pressure is not transmitted to the ventricle. The same type of pressure gradient is found when auricular fibrillation is present, and is diagnostic of tricuspid stenosis. If marked tricuspid incompetence is also present there is a definite atrial rise in pressure during ventricular systole (Chesterman and Whitaker, 1954 ; Whitaker, 1955).

\section{TREATMENT}

A major problem in treatment is to decide which valve should be operated upon first, as both tricuspid and mitral valves are usually involved together. Neptune and Bailey (1954), who did the first tricuspid valvotomy in 1952, have solved this difficulty by operating upon both valves at the same operation through a right-sided approach. Brock has operated upon the mitral, aortic, and tricuspid valves at one time by using a transverse sternal splitting incision. We have used this transverse sternal incision continued on both sides into the fourth intercostal spaces in Case 5, but previously we had endeavoured to decide which valve was responsible for the greater degree of incapacity and to operate upon that one first. If in doubt we prefer to operate upon the mitral valve first so that excessive pulmonary congestion will not take place. However, if the main disability is due to the raised systemic venous pressure as evidenced by the marked congestion of the face and head, we prefer to operate upon the tricuspid valve first. We reassess the patients at short intervals after operation and proceed to the second valvotomy if necessary when we feel maximum relief has been obtained from the first operation.

\section{RESULTS}

We have had five cases of proved tricuspid stenosis which we deemed needed tricuspid valvotomy. Three of these were submitted to mitral valvotomy first and one to tricuspid valvotomy as the initial operation. In the last case first mitral then tricuspid valvotomy were performed at the same operation.

CASE 1 (53/20397). -A married woman, aged 22, sought advice in May, 1953, as her disability was increasing and she was now breathless after climbing six steps. She had never suffered from nocturnal dyspnoea, haemoptysis, emboli, or congestive heart failure (Chesterman and Whitaker, 1954). She presented the typical features of both mitral and tricuspid stenosis. On June 16 a diaphragmatic mitral stenosis of $\frac{3}{4} \mathrm{~cm}$. long was split. She obtained some relief, but her exertional dyspnoea was but little changed. In October, 1953, she developed paroxysmal tachycardia and was readmitted as an emergency with loss of consciousness during an attack. This was attributed to the lessened output. 
On November 17, 1953, tricuspid valvotomy was done and the valve split from $\frac{3}{4} \mathrm{~cm}$. to about $3 \mathrm{~cm}$. Slight regurgitation was present but was unaffected by the operation.

Now (May 18, 1955) the patient is able to do all her housework and walk up hills.

CASE 2 (54/31536).-A married woman, aged 40, suffered from exertional dyspnoea which limited her walking to short distances on the level ; she complained particularly of congestion of the face. She was a classical case of tricuspid stenosis.

On April 13, 1954, tricuspid valvotomy was performed and the valve was split from $\frac{1}{2} \mathrm{~cm}$. to $3 \mathrm{~cm}$. Slight regurgitation, unaltered by the operation, was present.

When seen on May 17, 1955, her condition had greatly improved. She can do all her own housework and also goes out part time to a factory. She can walk normally on the level. Mitral valvotomy has not yet been considered necessary.
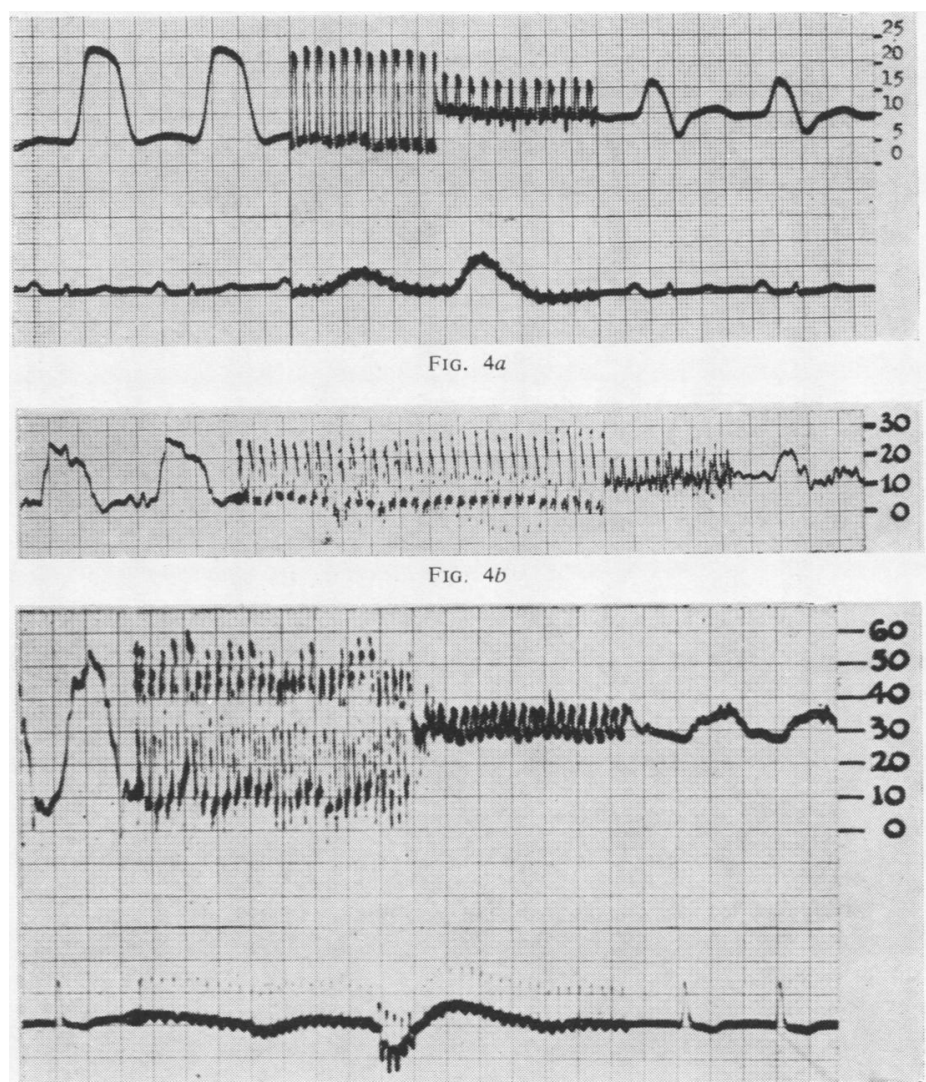

Fio. $4 c$

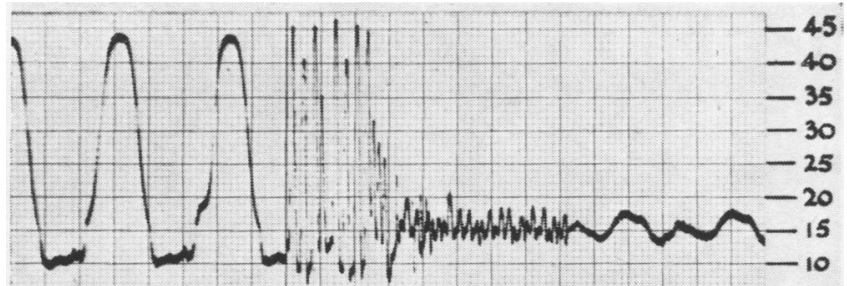

FIg. 4--Blood pressure records (mm. Hg) from the right ventricle and right atrium of patients with tricuspid stenosis. Case 2, tricuspid stenosis. Case 1, tricuspid and mitral stenosis. Case 4, tricuspid and mitral stenosis with pulmonary arterial hypertension. Case 3, tricuspid and mitral stenosis with auricular fibrillation. Case 5 , tricuspid and mitral stenosis with auricular fibrillation.

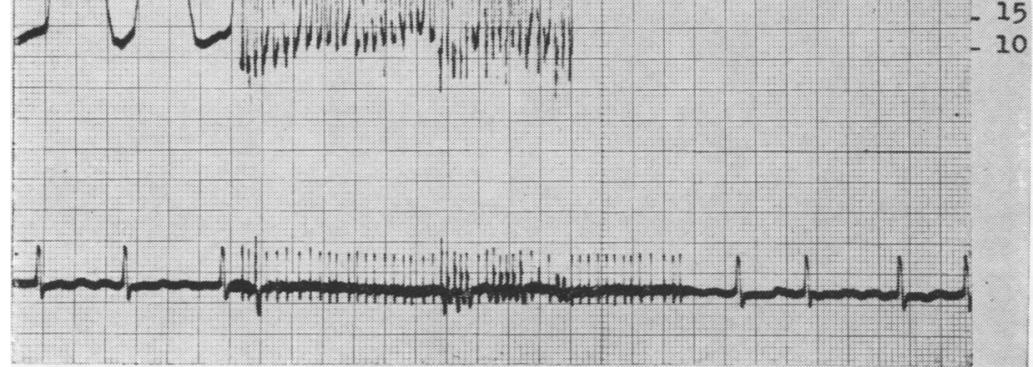

Fig. $4 d$

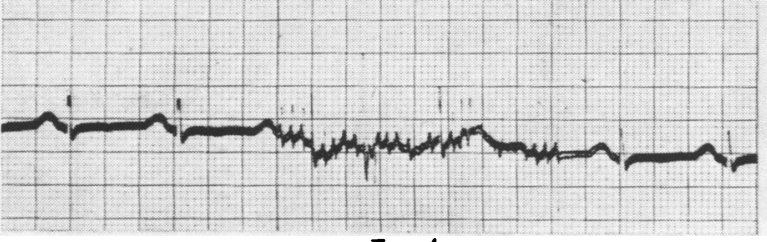


CASE 3 (54/34821). -A married woman, aged 39, had typical advanced mitral and tricuspid stenosis with auricular fibrillation and ascites for which she required frequent tapping. She had been refused operation in London one year previously.

On July 6, 1954, mitral valvotomy, and on September 21 tricuspid valvotomy, were performed; both showed an orifice of $1 \frac{1}{2} \mathrm{~cm}$. long and both split to $3 \mathrm{~cm}$. without any increase of the mild regurgitation already present. She made slow but steady progress until she developed bronchopneumonia (proved at necropsy) and died on December 12.

CASE $4(53 / 27631)$. - A married woman of 25 had suffered from congestive heart failure and subacute bacterial endocarditis early in 1954 after seven years of increasing breathlessness.

Her maximum cardiac output was 1.7 litres a minute and her mean pulmonary arterial pressure was $55 \mathrm{~mm}$. $\mathrm{Hg}$.

Mitral valvotomy was done on September 9, 1954, and the cusps were cut from $\frac{3}{4} \mathrm{~cm}$. to $2 \frac{1}{2} \mathrm{~cm}$. Unfortunately spontaneous respiration was never regained and she died in a respirator several hours later. Necropsy confirmed the tricuspid stenosis of $\frac{3}{4} \mathrm{~cm}$. orifice in length.

CASE 5 (54/41254). - A married woman of $33 \mathrm{had}$ been in congestive heart failure in October, 1954, when she refused operation but finally consented after a cerebral embolus in May, 1955.

She was a classical case of tricuspid and mitral stenosis with auricular fibrillation.

On July 27, 1955, mitral and tricuspid valvotomies were performed, each orifice being split from $1 \mathrm{~cm}$. to $3 \mathrm{~cm}$. in length. The immediate result showed marked improvement.

\section{OPERATION}

There are three points in regard to the actual operation which are worth mentioning.

First, the approach to the right atrium is made through a postero-lateral incision with resection of part of the fifth or sixth right rib, as this gives good access, less post-operative pain, and better reconstruction of the chest wall than a more anterior incision and also avoids the risk of oozing and sepsis in the breast. If, however, other valves besides the tricuspid may have to be dealt with at the same operation, then adequate exposure can be obtained by a bilateral intercostal incision in the fourth spaces joined by a $\mathrm{V}$ osteotomy of the sternum. This V-shaped osteotomy of the sternum, described by Brock, aids in accurate and easy closure.

Second, the approach to the valve often has to be made through the atrial wall rather than via the appendage. As in the left side of the heart when this is so, I have found that two pursestring sutures inserted to enclose an oblique field give the most satisfactory access available. The

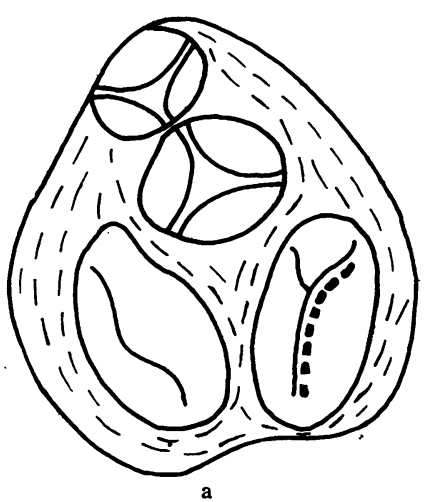

FIG. 5b.-Method of insertion of two tournique t sutures.

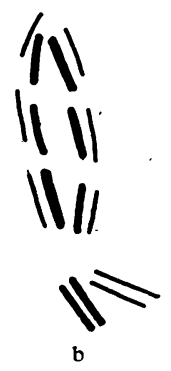

FIG. 5a.-Shows all valves on one plane and illustrates the analogy of the aortic mitral cusp to the infundibular and septal tricuspid cusps and points the suggested line of valvotomy.

Rumel tourniquets should lie towards the radial border of the finger which is used.

The last point is that the infundibular and septal cusps together correspond in function to the aortic cusp of the mitral valve, as they are adjacent to the outflow tract of the ventricle. Therefore, the split is better made between these two cusps on the one side and the marginal cusp on the other side. The primary site of regurgitation is at the junction of the cusps, and this may well be increased by an additional split between the infundibular and septal cusps. It follows that the safest place to start the split between the cusps is not where the three meet but between the septal and marginal cusps which are found to lie directly under the finger.

\section{CONCLUSION}

The diagnosis of tricuspid stenosis can now be made with accuracy, and surgical intervention gives encouraging results.

We acknowledge with gratitude the help of the Regional Cardiological Centre under Dr. J. W. Brown, the Professorial Medical Unit under Professor StuartHarris, Dr. E. K. Abbott, radiologist, and Dr. J. Johnston, anaesthetist.

REFERENCES

Altschule, M. D., and Blumgart, H. L. (1937). Amer. Heart J., 13,

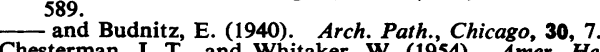

Chesterman, J. T., and Whitaker, W. (1954). Amer. Heart J., 48 631 .

Cooke, W. T., and White, P. D. (1941). Brit. Heart J., 3, 147.

Kossmann, C. E. (1955), Circulation, N.Y., 11, 378.

Neptune, W. B., and Bailey, C. P. (1954). J. thorac. Surg., 28, 15.

Rolleston, H. (1941). Brit. Heart J., 3, 1.

Smith, J. A., and Levine, S. A. (1942). Amer. Heart J., 23, 739.

Thompson, W. P., and Levine, S. A. (1937). Amer. J. med. ISci. $193,4$.

Whitaker, W. (1954). Quart. J. Med., 23, 105.

Wo (1955). Amer. Heart J., 50, 237.

Wood, P. (1950). Diseases of the Heart and Circulation. Eyre and Spottiswoode, London.

(1954). Brit. med. J., 1, 1051 and 1113. 